\title{
Customers' perceptions of returning items purchased online: planned versus unplanned product returners
}

Timo Rintamäki

Faculty of Management and Business, Tampere University, Tampere, Finland

Mark T. Spence

Bond Business School, Bond University, Gold Coast, Australia, and

Hannu Saarijärvi, Johanna Joensuu and Mika Yrjölä

Faculty of Management and Business, Tampere University, Tampere, Finland

\begin{abstract}
Purpose - The purpose of this study is to address two issues relevant to those managing product returns: (1) how customers perceive the returning process and assessing the extent that these perceptions have on satisfaction with the organization, loyalty and word-of-mouth (WOM) and (2) are these outcomes moderated by whether customer returns were planned or unplanned?

Design/methodology/approach - The data consisted of 21 semi-structured interviews (pilot study) and a quantitative survey ( $n=384$; main study) targeted at consumers who had bought fashion items online.

Findings - Qualitative insights revealed that perceptions of the returning experience are driven by monetary costs, convenience, stress and guilt. Quantitative findings showed that the returning experience explains return satisfaction for both planned and unplanned returners, and returning satisfaction explains overall satisfaction and WOM. The noteworthy difference concerns loyalty: although customers that planned to return items are more loyal to the organization, it is the unplanned returners whose loyalty can be significantly increased by better managing the returning process.

Practical implications - Returning products online is increasingly common and thus forms an important part of the customer's overall experience with an organization. Returns management can therefore drive key customer outcomes. Understanding the dynamics between the product return experience, return satisfaction and customer outcomes will help practitioners design and implement more informed returns management strategies. Measures are also presented that assess the cognitive and emotional aspects associated with returning products.

Social implications - Returning products is an increasingly important challenge for online retailers. Understanding what kinds of returning behaviors occur allows companies to design and execute better informed decisions to manage this phenomenon, not only for the sake of firm performance but also for societal and environmental benefits - the triple bottom line.

Originality/value - While scholars have investigated the relationship between return policies (e.g. free vs fee) and profitability, no prior literature has examined the returning experience: how consumers perceive the returning process; motivations for their returns (whether returns were planned or not) and subsequent customer outcomes.
\end{abstract}

Keywords Online retailing, Returning experience, Returning satisfaction, Planned versus unplanned returns, Product returns, Returns management

Paper type Research paper

C Timo Rintamäki, Mark T. Spence, Hannu Saarijärvi, Johanna Joensuu and Mika Yrjölä. Published by Emerald Publishing Limited. This article is published under the Creative Commons Attribution (CC BY 4.0) licence. Anyone may reproduce, distribute, translate and create derivative works of this article (for both commercial and non-commercial purposes), subject to full attribution to the original publication and authors. The full terms of this licence may be seen at http://creativecommons.org/licences/by/4.0/ legalcode

The authors would like to thank the reviewers for their constructive comments on this paper.

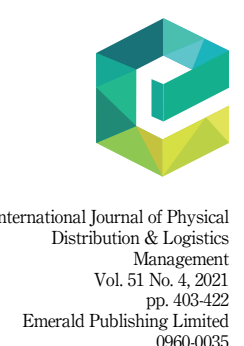

DOI 10.1108/JPDLL10 0960-0035
Received 6 October 2019

Revised 30 August 2020 9 February 2021

Accepted 11 February 2021 
IJPDLM 51,4

404

\section{Introduction}

The importance of a customer focus to those responsible for logistics management was acknowledged three decades ago (Fuller et al., 1993). Logistics is now regarded as an important means to create a competitive advantage (Daugherty et al., 2019; Gligor et al., 2020; Markley and Davis, 2007). One key driver of a customer focus in logistics has been the growth of Internet retailing, which has resulted in an explosion in product returns. "If merchandise returns were a company it would rank number three on the Fortune 500", representing $8 \%$ of total sales or over $\$ 260 \mathrm{bn}$ in lost sales for US retailers (National Retail Federation, 2015, p. 3). For online retailers return rates are even more dramatic, exceeding $22 \%$ (Rao et al., 2018; Walsh and Brylla, 2017). Altogether, the volume of returned items is substantial, making reverse logistics in general and returns management in particular, increasingly important areas of management for retailers (Daugherty et al., 2019; Hjort et al., 2019; Robertson et al., 2020). As Hjort et al. (2019) argue, the cost focus in returns management has moved to value recovery and to customer value creation (see also Rogers and Tibben-Lembke, 2001; Mollenkopf et al., 2011 and Griffis et al., 2012). This shift in focus emphasizes the strategic role that returns management can have in gaining a competitive advantage by contributing to key customer outcomes, such as satisfaction, word-of-mouth (WOM) and loyalty.

Despite the cost of processing returned products, the general tendency is for online retailers to offer lenient return policies because the sales stimulated by lenient policies more than compensates for the costs associated with processing returns (Janakiraman et al., 2016; but see Hjort and Lantz, 2016, for an alternative view). For consumers, lenient return policies serve as a signal of product quality (Wood, 2001) as well as reduce risks associated with online purchases (Mollenkopf et al., 2007; Petersen and Kumar, 2015). Whether lenient or not, return policies are now considered an important part of online retailers' overall offering together with wide selections, affordable prices and fast delivery times. Within the European Union online purchases may be returned for any reason within 14 days for a full refund (European Union, 2019). In these countries, returning items is thus a right, free of moral judgment or requiring any legitimate reason for returns, such as the retailer shipping the wrong size or the item being defective.

Given that online retailers continue to gain share from traditional brick-and-mortar firms, it is not surprising that scholars have endeavored to shed light on the linkage between online retailers' return policies, returning proclivity (Janakiraman et al., 2016; Wood, 2001) and firm performance (Bower and Maxham, 2012; Griffis et al., 2012; Hjort and Lantz, 2016; Mollenkopf et al., 2007; Petersen and Kumar, 2009), an important firm-centric perspective. There is also a growing interest in examining the relationship between product returns and customer outcomes, such as satisfaction with the organization (Walsh and Brylla, 2017). Absent from current discourse is how customers perceive the returning process, which can be effortful and emotion laden, and how these perceptions influence their relationship with the retailer - and ultimately profitability. This is surprising because, should a customer return an item, the returning process contributes to the overall customer experience. Consequently, shedding insight into how customers perceive the returning process and assessing the extent that these perceptions have on satisfaction with the organization, loyalty and WOM is the primary research objective herein.

The second research objective is to determine if the reason for returning an item(s) moderates the relationship between perceptions of the return process and satisfaction, loyalty and WOM. The nefarious side of returning behavior has received particular attention, variously labeled as retail borrowing (Piron and Young, 2001), deshopping (King et al., 2007) and fraudulent returning behavior (Harris, 2008). But not all returns are of a fraudulent nature, that is "knowing that such a return is contrary to the firm or legal 
rules and regulations ...”, such as returning used or consumer damaged goods (Harris, 2008, p. 461). A far less critical view suggests that most returns are due to some form of service quality failure on the part of the retailer, such as the product being defective or the wrong item being shipped (Ertekin, 2018; Mollenkopf et al., 2007). Qualitative insights by Saarijärvi et al. (2017) revealed 22 reasons for returning items, most of which would be considered unplanned. But that is not always the case. For example, some customers intentionally order more products than they intend to keep, what we call planned returners. This type of behavior especially strains reverse logistics causing not only unnecessary costs but also has environmental ramifications (Markley and Davis, 2007; Rogers and Tibben-Lembke, 2001).

Here, we assess the moderating effect of whether product returns were planned (e.g. ordering multiple items with the intentions of only keeping a subset) versus unplanned (e.g. the product was defective or the wrong size). Intuition would suggest that someone that returns an item for a legitimate reason is probably more valuable to a firm than is someone intending to return items because the cost of serving the latter would likely be higher; but an alternative view is that a service failure (prompting an unplanned return) may lower satisfaction/loyalty, hence lower lifetime value. Prior studies examining the implications of product returns rarely make the distinction between what we refer to as planned versus unplanned returners, hence this is a novel customer segmentation perspective.

The two overarching research objectives are summarized in the four questions:

(1) What factors affect perceptions of the returning process?

(2) How do perceptions of the returning process affect satisfaction with the returning process?

(3) How does satisfaction with the returning process affect satisfaction with the organization, loyalty and WOM?

(4) Are the relationships specified in points 2 and 3 moderated by whether customer returns were planned or unplanned?

To address these research questions, we first review literature related to returning behavior and what little is known regarding perceptions of the returning experience. Should a customer return an item(s), their perception of the returning process forms part of the overall customer experience. As Ertekin (2018, p. 121) cogently notes: "Effective and efficient management of customer interactions is increasingly being recognized as a source of sustainable advantage..." Second, while prior research does not consider emotions related to the returning process (Mollenkopf $e$ t al., 2007), we share qualitative insights from a pilot study that revealed stress and guilt affect perceptions of the returning process. Third, a conceptual model linking the return experience to satisfaction with the firm, loyalty and WOM via satisfaction with the returning process is introduced and empirically assessed. Whether the returns were planned or unplanned is tested as a moderating variable. Theoretical and managerial implications complete the paper.

Good research should address a topical and relevant phenomenon (Mollenkopf, 2014). In that respect, returning behavior is an evolving and increasingly important characteristic of e-commerce. For example, it is estimated that Zalando, one the largest online retailers in the world, has return rates around $50 \%$. This, together with the fact that fashion merchandise represents the largest e-commerce segment and its sales are expected to grow over $11 \%$ per year, reaching $\$ 700$ bn by 2022 (Postnord, 2016; Statista, 2018), showcases the magnitude of this timely phenomenon, raising its relevance for both scholars and practitioners in the field of consumer behavior as well as retail logistics management.
Perceptions of returning items purchased online

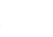


IJPDLM

51,4

406

\section{Literature review}

\section{Customer returns and returns management}

Customer returns are the largest category of returns (other categories include, e.g. product recalls and environmental returns). Customer returns exert pressure on managing the reverse flow of products effectively and balancing customer needs and firms' costs emerging from various activities related to returned items. Returns management consists of cross-functional processes, for example, customer relationship management, customer service management and order fulfillment, that contain strategic and operational elements (Rogers et al., 2002). For our purposes, the strategic level is deemed the more important of the two, as it defines the goals and guidelines for operative returns management. Over time the goals of returns management have evolved from a cost focus to recapturing value (e.g. by reselling products) to creating customer value and other relevant relationship outcomes (Hjort et al., 2019). Strategic guidelines have been described through avoidance, gatekeeping and disposition (Rogers et al., 2002). Whereas gatekeeping sets criteria and screening for returns, and disposition is concerned on what to do with the returned products (e.g. resell or recycle), avoidance focuses on techniques that would minimize product returns. Sales techniques, product quality, better customer segmentation and enhanced purchase information are examples that can help in adjusting customer expectations and hence achieving avoidance goals.

Perhaps the single most important way to pursue avoidance goals is through the return policy. Return policies play an important role in forming customer expectations of return control, which affects attitudes and behaviors (Dailey and Ülkü, 2018). In a metaanalysis of 21 studies, Janakiraman et al. (2016) concluded that there are five dimensions that underlie how lenient return policies are, and that these dimensions differentially affect purchases (e.g. money and effort leniency stimulate purchases) versus return proclivity (stricter time and exchange leniency reduce returns). But they note (Janakiraman et al., 2016, p. 226), "overall, leniency increases purchase more than return." Managing return behavior, in turn, influences firm performance. For example, refund speed has been shown to increase order frequency, item value and order size (Griffis et al., 2012). A field study conducted by Petersen and Kumar (2015) provides further evidence regarding the importance of considering product returns in customer lifetime value (CLV) calculations. While product returns incur a cost, from the customer's perspective it can stimulate sales and reduce the firm's subsequent marketing costs. Managers also recognize that flexibility and ease of product returns are important aspects of providing good customer service (de Leeuw et al., 2016). Effectively dealing with returns - a service failure if the retailer is at fault - is thus an opportunity for the retailer to further cultivate a relationship with the customer (Griffis et al., 2012; Mollenkopf et al., 2007; Ertekin, 2018, in an offline context). How returns are dealt with can therefore create value for the customer or destroy it (Vakulenko et al., 2018).

Consider monetary refunds, one of the five return policy dimensions identified by Janakiraman et al. (2016). Bower and Maxham (2012) found that the cost of returns (free versus fee) affects perceptions of fairness and subsequent customer spending. If a customer thought they were treated unfairly (or particularly well), they are likely to have emotional reactions. Lenient return policies may influence purchase decisions (Petersen and Kumar, 2015); for example, one may order multiple items with the intentions of only keeping a few (Saarijärvi et al., 2017; Harris, 2008, 2010). Customers that take into consideration a firm's return policy at the time of purchase may therefore have a different overall experience compared to another customer who did not consider the return policy until postpurchase. Returning goods can have unintended consequences for both seller and buyer. Ertekin (2018) speculates - but does not test - that returning products may be stressful or guilt ridden. It is reasonable to assume that cognitions and emotions could be in conflict: one may feel guilty 
about returning an item despite acknowledging that the process of returning the item was easy, or vice versa. Altogether, customers returning items are likely to experience emotional reactions as well as cognitive responses, which sets the stage for considering the returning process through the concept of the "returning experience", a subcomponent of the overall customer experience (Cassill 1998; Grewal et al., 2009; Verhoef et al., 2009) [1]. A purpose of this research effort is therefore to close a gap identified by Ertekin (2018, p. 123): "From a theoretical perspective, we observe the academic literature considers the return experience a black box ....".
Perceptions of returning items purchased online

\section{Returning experience, returning satisfaction, and customer outcomes}

Prior literature has not considered the returning experience as a separate construct, as an antecedent to firm metrics such as overall satisfaction and loyalty; however, ample evidence has emerged showing that how lenient are a firm's return policies affects consumers' online returning behaviors and subsequent purchases. For example, Bower and Maxham (2012) concluded that free returns increased postreturn sales, whereas charging a fee to return products decreased postreturn purchases. The general view is that lenient return policies stimulate more purchases than returns (Janakiraman et al., 2016) and are thus a means to create a competitive advantage (Griffis et al., 2012). From the consumer's perspective lenient policies mitigate the risk that is often associated with online retailing (Mollenkopf et al., 2007; Petersen and Kumar, 2015; Saarijärvi et al., 2017), particularly when dealing with experience goods where essential information is missing at the time of making the purchase (Wood, 2001).

Delivering a meaningful customer experience is a means to satisfy customers and achieve competitive advantage (McColl-Kennedy et al., 2019; Verhoef et al., 2009); hence, understanding the ramifications of the elements driving the customer experience is important for both scholars and practitioners (Lemon and Verhoef, 2016). For those customers that return goods purchased online, the returning experience is a component of the customer's overall experience with the organization. Purchasing merchandise online is a two stage, temporally separated process: making the purchase decision and then deciding whether to keep the item (Wood, 2001). For experience or high touch goods, such as fashion merchandise, key information is missing at the time of purchase; thus, for a variety of reasons consumers often return some or all of the ordered items. The returning experience is bounded by the firm's return policies and the touchpoints that the process of returning items entails.

Touchpoints include all verbal and nonverbal interactions that a consumer relates to a firm, and may be direct or indirect (Baxendale et al., 2015). In online shopping, having to go to the post office to return a good and the interactions that occur there are outside the firm's control, but nevertheless are linked to the focal organization, hence affect the customer's experience. Touchpoints take many forms, including physical environments, personal interactions and online platforms (Ieva and Ziliani, 2018). The customer experience emerges over time as a result of the many touchpoints occurring during prepurchase, purchase and postpurchase stages (Homburg et al., 2017; Frow and Payne, 2007). According to Lemon and Verhoef (2016, p. 71; see also Verhoef et al., 2009; Bustamante and Rubio, 2017), the "customer experience is a multidimensional construct focusing on customer's cognitive, emotional, behavioral, sensorial and social responses to a firm's offerings during the customer's entire purchase journey". The customer's overall experience thus emerges from chronologically dispersed touchpoints and incorporates a multitude of responses.

In the context of online retailing, the returning process would include touchpoints such as repackaging, going to the post office and receiving a refund/credit. Although these 
IJPDLM 51,4

touchpoints occur postpurchase, they influence the overall experience. Returning a product therefore extends the customer experience. The context studied here is sales of fashion merchandise, the most popular online product category both in terms of purchases and returns (Statista, 2018; Optoro, 2018), hence the return experience and its respective touchpoints should not be ignored by retailers.

Given the important role that return policies have on affecting return proclivity, it is surprising the paucity of research that addresses the influence of the returning experience on customer outcomes. In an offline context, Cassill (1998) found that recent returns (i.e. within one month) enhanced product and shopping experience satisfaction (through friendliness of the sales associate, the degree that the shopper was made to feel trusted, the fairness of the return policy and the quickness of the return process). More recently, Ertekin (2018) has shown that in-store return experience (perceived salesperson competency, selling pressure) has the potential to affect not only satisfaction with the returning process but future purchases as well. Mollenkopf et al. (2007) take a broader supply chain management perspective within an online context. They advance factors thought to affect "service recovery quality" (e.g. compensation offered and ease of identifying online or offline assistance) and showed that these are positively related to satisfaction with the returning experience and then to loyalty. However, absent from their analysis are emotions associated with the returning process as well as differentiating customers based on their reasons for returning merchandise. In one of the few studies specifically focused on customer outcomes, Walsh and Brylla (2017) found that customer's estimates for the percentage of products they returned was negatively related to satisfaction and WOM, which contradicts the general view that offering lenient return policies is advantageous (Janakiraman et al., 2016) - but these authors did not control the reason for why products were returned. Furthermore, they did not take into consideration perceptions of the returning experience or return satisfaction (although they did measure overall satisfaction with the firm); thus, a question remains whether better managing the returning experience can help companies improve customer relationships. We propose that satisfaction with the returning process is a result of one's returning experience, and thus is an independent construct; and that return satisfaction in turn affects key customer outcomes, specifically overall satisfaction with the organization, loyalty and WOM.

\section{Conceptual framework}

Based on the above discussion, we advance and test the conceptual model shown within the dashed box of Figure 1. The proposed model thus lies between return policy leniency, returning behavior/proclivity and firm performance, constructs that have been studied in prior literature (c.f., Hjort and Lantz, 2012, 2016; Janakiraman et al., 2016; Petersen and Kumar, 2009; Saarijärvi et al., 2017). The model links returning experience to returning satisfaction, and then to customer outcome measures, namely, satisfaction with the organization, loyalty and WOM. The proposed model starts with the returning experience, an important and little understood construct (Ertekin, 2018). Returning an item, hence the experience realized with the process, is stimulated by antecedents, including the reason for returning the item and the leniency of the returning process. The customers' responses, perceptions of the returning experience and return satisfaction, produce outcomes relevant to retailers, namely, satisfaction, loyalty and WOM.

Scholars have shown that customers that do not return items are more profitable relative to those that do, and have therefore proposed that not all customers should be extended the same return policy (Hjort and Lantz, 2016; Petersen and Kumar, 2009). However, these studies are based on a coarse separation: those customers that do versus do not return items. Segmenting at such a high-level seems crude considering that returns can range from being 


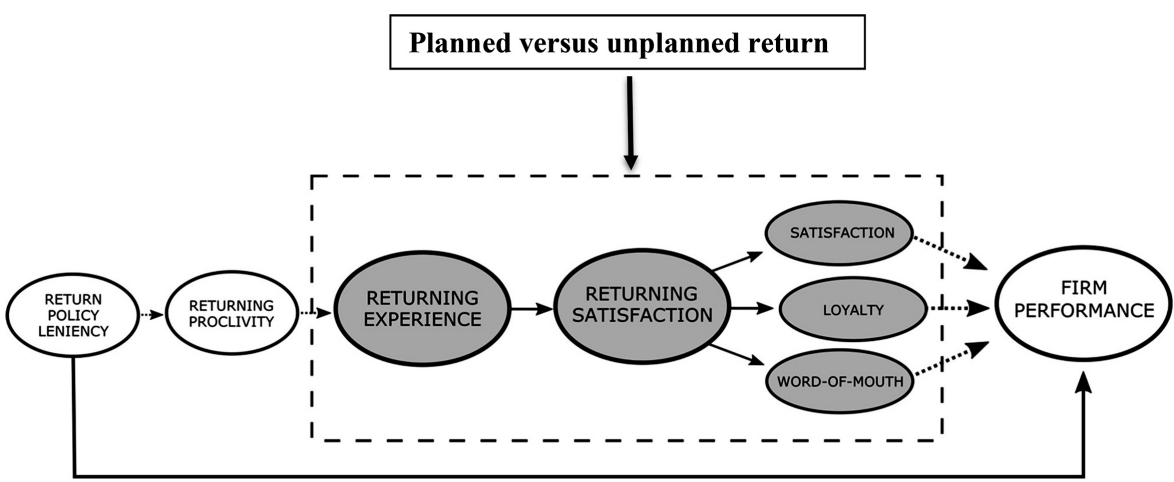

unplanned (e.g. a wrong-sized product was delivered) to being intentional (Harris, 2008; Saarijärvi et al., 2017; Walsh and Brylla, 2017). Intuition would suggest that someone that returns an item because of a service failure from the organization (wrong size delivered) is different than is someone that intended to return items (ordered multiple shirts with the intentions of only keeping one). Whether returns were planned versus unplanned is tested as a moderating variable.

\section{Methodology}

To empirically assess the ramifications of the consumer's returning experience, a two-study approach was employed. First, an exploratory pilot study was conducted that focused on uncovering the dimensions associated with the returning experience, thus shedding insight into how to measure returning experience. Second, a quantitative study was executed to model and measure the effect of customers' online returning experiences on well-established customer outcome measures (refer to Figure 1). Both studies were conducted in Finland.

\section{Pilot study}

The purpose of the pilot study was to explore how consumers - in their own words - perceive the returning process. The goal was to unearth the cognitive and emotional responses participants experienced when returning goods purchased online. To achieve this, 21 semistructured interviews were conducted with consumers who had purchased fashion items online at least four times during the past year and had returned at least one item. The participants for the pilot study were recruited through an announcement at a university in Finland, and included both staff members and students (18 females, mean age $=29.4 ; 3$ males mean age $=24.7$. While the participants are arguably not a representative sample of all Finnish online consumers, there was a wide age range and all had experience buying fashion online, which is especially popular among young female consumers. (As it turned out, $88 \%$ of those that returned fashion items in the main study were females, a similar percentage of females in the pilot study).

Through a predesigned set of questions respondents were encouraged to speak freely about their fashion online buying behavior in general and their returning behaviors in particular. For example, the respondents described in detail their respective online buying processes including why and how they returned fashion items. However, the focus was not on identifying what was the price, brand or store of the purchase, but instead uncovering the 
IJPDLM 51,4

\section{0}

various reasons for returning fashion items and how the respondents felt about the returning process. All interviews were recorded and transcribed.

Data analysis was conducted in two phases. First, the authors read the transcribed interviews to get an overall picture of the extent to which the data captured and described consumers' returning experiences. Second, a deeper exploration of the reported experiences was conducted. At this phase three academics skilled in qualitative analysis coded iteratively the open-ended responses into a parsimonious set of categories that captured the various comments associated with the returning experience. While coding categories have not been advanced by prior scholars, the authors looked into literature that speculated on possible categories (e.g. Ertekin, 2018, who suggested that guilt may be a factor). This phase resulted in four categories: monetary costs, convenience, stress and guilt. Table 1 summarizes these four categories with illustrative quotes from the interviewees.

The first category is monetary costs. Past studies have shown that free versus fee returns affects behaviors (Bower and Maxham, 2012). The relevant quotes illustrate the salience of cost when returning items, and that some consumers understand the costs prior to purchase. The second category relates to convenience or lack thereof, as they describe the time and effort needed to return the ordered item(s). The third category is stress and refers to negative emotions and feelings resulting from returning items. Stress stemmed from the emotional cost of the time pressure and the process of repacking the items and sending them back to the retailer. Finally, guilt was associated with the recognition that their returning a product is a cost to the company. Moreover, some shoppers perceive that returning items is normatively inappropriate, thus spurring guilt. We believe this pilot study is among the first to provide insights into the emotions experienced due to returning items.

\begin{tabular}{ll}
\hline & Quotes from interviewees \\
\hline $\begin{array}{l}\text { Monetary } \\
\text { costs }\end{array}$ & "This one time, a while back, when I ordered a top from England and it turned out to be not \\
that great, I ended up paying for the return and the postage." \\
"Nowadays I'm not that keen to return stuff because they've made it chargeable in many \\
places, so the piece of clothing will cost me quite a lot if I decide to return it." \\
"I mean, if I cannot return it free of charge then I do not order in the first place." \\
Convenience \\
"It always seems as if it's an agonizing effort to drag the bag to the post office." \\
"You just stick the return label on the package and then take it to the post office and that's \\
pretty much it. It's quite an easy system." \\
"Well somehow the idea itself feels cumbersome. The whole idea of ordering while knowing \\
you're going to have to return something, somehow it feels cumbersome. I know it in \\
advance." \\
"Mostly the fear that you will not miss the deadline." \\
"The returning process is an annoyance. I mean sure you usually only have to take the \\
package to the post office or something, but still it somehow always feels so heavy." \\
"Well, it is always a painful thing, but well... or it's not really painful, but it's always \\
somehow tedious to return stuff. I mean it's always nice to pick up the package, but then it's \\
annoying to take it back ..." \\
"Those couple of times that I've left a return package at the post office, I've been like, it's not \\
that cool. .. for the company, I mean. But I get over it fast. So, I just got a guilty conscience \\
".." \\
"I thought that this is a bit nasty for the company when I go and order and return just for the \\
fun of it." \\
"Maybe there's some kind of a moral awareness or then I have this ingrained idea in me that if \\
I buy something, then it's mine."
\end{tabular}

\section{Table 1.}

Identified categories with respective illustrative quotes from the pilot study interviews 
The main study

Data collection. Data were collected via an online questionnaire. A market research agency was hired to ensure a representative sample of Finnish Internet users (the organization is ISO20252 certified and follows the ICC/ESOMAR International Code of Marketing and Social Research Practice). Respondents were screened for online fashion shopping. The respondents were asked to think back to a recent online fashion shopping experience (within 12 months) and specify the retailer in question by picking it from a list of common national and international stores, or if the store they dealt with was not on the list to type in the name of the retailer. Participants were therefore not restricted to a particular store, product line or brand, which was intentional, to increase the likely range of the customers' experiences. Of the 1358 respondents that indicated they had purchased fashion items online during the past 12 months, $384(28.3 \%)$ respondents had returned at least one item from their most recent online shopping experience. This percentage of returners is in line with previous research (Postnord, 2016; Statista, 2018). Table 2 presents the demographic profiles of the entire dataset and those that returned items. Chi-square tests show that those who returned items were more likely to be female, 26-40 years old, and have a higher frequency of purchases than those that did not return items. The focus here is on those individuals that returned at least one of the items purchased $(n=384)$.

Measures. Drawing from the results of the pilot study as well as previous literature, a questionnaire was developed to measure and model the key concepts. Return experience is a reflective construct that captures the four underlying dimensions revealed in the qualitative pilot study: monetary costs, convenience, stress and guilt. This perspective focuses on the reactions to the returning process from the customer's perspective instead of evaluating the elements of firm's return policies, such as the amount of time allowed to return an item, and thus broadens earlier research efforts from rational to emotional factors. Return satisfaction was measured with a single-item similar to that used by Ertekin (2018) in an offline context [2]. Satisfaction with the organization, loyalty and WOM measures were all measured with
Perceptions of returning items purchased online

\begin{tabular}{|c|c|c|c|c|c|c|}
\hline \multirow[b]{3}{*}{ Gender } & \multicolumn{2}{|c|}{ Complete data } & \multicolumn{2}{|c|}{ Returned an item(s) } & & \\
\hline & $N$ & $\%$ & $N$ & $\%$ & & \\
\hline & & & & & & \\
\hline Female & 1025 & $75.5 \%$ & 337 & $87.8 \%$ & $X^{2}(1)=42.71$ & \\
\hline Male & 333 & $24.5 \%$ & 47 & $12.2 \%$ & $p<0.001$ & \\
\hline Total & 1358 & $100 \%$ & 384 & $100 \%$ & & \\
\hline Age & & & & & & \\
\hline 25 years or younger & 120 & $8.8 \%$ & 28 & $7.3 \%$ & $X^{2}(4)=13.12$ & \\
\hline $26-40$ years & 468 & $34.5 \%$ & 159 & $41.4 \%$ & $p=0.011$ & \\
\hline $41-55$ years & 518 & $38.1 \%$ & 139 & $36.2 \%$ & & \\
\hline $56-70$ years & 212 & $15.6 \%$ & 50 & $13.0 \%$ & & \\
\hline 71 years or older & 40 & $2.9 \%$ & 8 & $2.1 \%$ & & \\
\hline Total & 1358 & $100 \%$ & 384 & $100 \%$ & & \\
\hline Frequency of purchases & & & & & & \\
\hline Weekly & 8 & $0.6 \%$ & 1 & $0.3 \%$ & $X^{2}(4)=30.17$ & Demographic profile of \\
\hline Monthly & 159 & $11.7 \%$ & 67 & $17.4 \%$ & $p<0.001$ & $\begin{array}{l}\text { online fashion }\end{array}$ \\
\hline Few times a year & 883 & $65.0 \%$ & 258 & $67.2 \%$ & & shopping respondents \\
\hline Once a year & 231 & $17.0 \%$ & 45 & $11.7 \%$ & & and those that returned \\
\hline Less frequently & 77 & $5.7 \%$ & 13 & $3.4 \%$ & & an item from their last \\
\hline Total & 1358 & $100 \%$ & 384 & $100 \%$ & & shopping experience \\
\hline
\end{tabular}


IJPDLM 51,4

412 three-item scales using positive wording adapted from previous research (Jones and Reynolds, 2006; Mägi, 2003).

Outer model evaluation. SmartPLS 3.0 was used for analysis purposes (Ringle et al., 2015). Partial least squares (PLS) path modeling was deemed appropriate because it can accommodate small sample sizes and non-normally distributed data (Chin and Newsted, 1999; Henseler et al., 2009). For example, some analyses separately study planned versus unplanned returners, the former of which consists of 73 respondents, a sample considered too small for SEM software such as LISREL. Furthermore, Henseler et al. (2009) note that PLS is ideal for causal-predictive analysis in situations of high complexity but low theoretical formation. The conceptual model tested here is novel, utilizing some established constructs but extends theory by introducing new constructs and measures. The bootstrap technique was used to determine confidence intervals for all parameter estimates (the number of bootstrap samples was set at 5000). SPSS Statistics 23 was employed for post hoc analyses.

Harman's single factor test was used to test for common method variance. Exploratory factor analysis with principal component analysis (PCA) was conducted in SPSS. Fourteen distinct factors emerged with the first three explaining $76.9 \%$ of the variance. Being aware of the likely correlative nature of the constructs the procedure of partialling out a marker variable was run using SmartPLS (Tehseen et al., 2017). A six-item measure of Environmental Awareness was collected in the same survey and was used as the marker variable. Correlations between the marker variable and constructs were small $(r<0.11)$ and nonsignificant. The differences between $R^{2}$ values for each construct before and after adding the marker variable were less than 0.006 , which permits us to assume that common method variance is not a concern.

All measures appear in Table 3 along with their indicator loadings and $t$-statistics (two-tailed test) relative to their respective constructs. With the exception of the fourth returning experience measure that taps guilt (loading equals 0.622 ), all loadings exceeded

\begin{tabular}{lcc}
\hline Returning experience (new measure) & Loadings & $t$-statistics \\
\hline The returning process did not cause any monetary costs & 0.773 & 18.78 \\
The returning process was convenient & 0.898 & 58.92 \\
The returning process did not cause stress & 0.887 & 51.07 \\
The returning process did not make me feel guilty & 0.622 & 9.47 \\
Returning satisfaction (new measure) & & \\
In general, how satisfied are you with the returning process? & 1.000 & - \\
Satisfaction with the organization (adapted from Mägi, 2003) & & \\
What is your overall satisfaction with [the online shop]? & 0.924 & 86.43 \\
To what extent has [the online shop] met your expectations? & 0.914 & 53.67 \\
How well did [the online shop] compare with the ideal type of online fashion retailer? & 0.868 & 44.48 \\
Loyalty (adapted from Jones and Reynolds repatronage intentions measure, 2006) & & \\
I am likely to buy fashion in this shop in the future & 0.981 & 261.30 \\
If possible I will continue buying fashion in this shop in the future & 0.969 & 96.73 \\
I intend to buy fashion in this shop in the future & 0.975 & 201.55 \\
Word of mouth (adapted from Jones and Reynolds, 2006) & & \\
I am likely to say good things about this online shop & 0.962 & 151.49 \\
I would recommend the online shop to my friends and relatives & 0.981 & 230.39 \\
I would recommend the online shop to others & 0.983 & 359.93
\end{tabular}

I would recommend the online shop to others
Table 3.

Measurement scales with indicator loadings and $t$-statistics (all measures are 7-point scales) 
0.70; however, Henseler et al. (2009) recommend that indicators with loadings greater than 0.4 should be retained.

As shown in Table 4, the composite reliability for each construct exceeds 0.70 and thus it is deemed satisfactory. Average variance of extracted (AVE) was calculated to assess convergent validity. The AVE varies between 0.64 and 0.95 , and thus it is adequate (Henseler et al., 2009; Hair et al., 2011). Using the Fornell-Larcker criterion to detect discriminant validity of the constructs, the square root of AVE for each construct (in italics on the diagonal, Table 4) is larger than its correlation (off-diagonal elements) with other constructs (Fornell and Larcker, 1981), hence the constructs are independent.

Inner model evaluation. All paths in the structural model are positive and significant (see Table 5; all $p$ 's $<0.01)$. The analysis reveals that the path coefficient from returning experience to returning satisfaction is significant $(\beta=0.765 ; p<0.01)$. Furthermore, returning satisfaction significantly affects all the customer outcome variables (satisfaction, loyalty and WOM). Evaluating effect size using Cohen's (1988) $f^{2}$ reveals that returning satisfaction has a large effect on purchase satisfaction $\left(f^{2}=0.404 ; p<0.01\right)$ and a moderate effect on loyalty and WOM. The $R^{2}$ values for the endogenous latent variables are $0.288,0.217$ and 0.197 , respectively, for the three outcome variables and thus should be interpreted as weak (Chin, 1998). While collectively the effects may be small, they are not inconsequential (Hair et al., 2011): how customers perceive the return experience has a ripple effect on key customer outcomes via return satisfaction. The returning experience is a component affecting the customer's overall experience, which could explain the relatively low $R^{2}$ values; nevertheless, these findings show that it is a construct meriting attention by retailers when developing return policies. Shedding light on how customers perceive the returning process and the ramifications that this has on satisfaction with the organization, loyalty and WOM was the first research objective

Model confirmation. To confirm that return satisfaction mediates the relationship between return experience and the three outcome measures, the paths associated with this model (model 1 in Table 6) were compared to two other models: a reduced model directly linking return experience to the outcome variables (model 2), and an expanded model that included both the direct effect of return experience on the outcome variables as well as the indirect effects via the proposed mediator, return satisfaction (model 3). In all cases, the path

\begin{tabular}{|c|c|c|c|c|c|c|c|c|}
\hline & AVE & $\mathrm{CR}$ & (1) & (2) & (3) & (4) & (5) & Table 4. \\
\hline $\begin{array}{l}\text { Returning satisfaction (1) } \\
\text { Returning experience (2) } \\
\text { Satisfaction (3) } \\
\text { Loyalty (4) } \\
\text { Word of mouth (5) } \\
\text { Mean } \\
\text { s.d. }\end{array}$ & $\begin{array}{c}- \\
0.644 \\
0.814 \\
0.951 \\
0.951\end{array}$ & $\begin{array}{c}- \\
0.877 \\
0.929 \\
0.983 \\
0.983\end{array}$ & $\begin{array}{l}1 \\
0.765 \\
0.536 \\
0.466 \\
0.444 \\
5.96 \\
1.18\end{array}$ & $\begin{array}{l}0.803 \\
0.426 \\
0.398 \\
0.397 \\
6.03 \\
1.15\end{array}$ & $\begin{array}{l}0.902 \\
0.637 \\
0.732 \\
5.05 \\
1.09\end{array}$ & $\begin{array}{l}0.975 \\
0.697 \\
5.63 \\
1.47\end{array}$ & $\begin{array}{l}0.975 \\
4.98 \\
1.57\end{array}$ & $\begin{array}{r}\text { Average variance } \\
\text { extracted (AVE), } \\
\text { internal consistency } \\
\text { reliability (CR), } \\
\text { discriminant validity, } \\
\text { means and standard } \\
\text { deviations of } \\
\text { constructs }\end{array}$ \\
\hline
\end{tabular}

\begin{tabular}{lcrrr}
\hline & Estimated path coefficient & $t$-statistics & $R^{2}$ & $f^{2}$ \\
\hline Returning experience $\rightarrow$ Returning satisfaction & 0.765 & 21.306 & 0.585 & 1.410 \\
Returning satisfaction $\rightarrow$ Purchase satisfaction & 0.536 & 11.739 & 0.288 & 0.404 \\
Returning satisfaction $\rightarrow$ Loyalty & 0.466 & 9.511 & 0.217 & 0.277 \\
Returning satisfaction $\rightarrow$ Word of mouth & 0.444 & 9.720 & 0.197 & 0.245
\end{tabular}

Perceptions of returning items purchased online 


\begin{tabular}{|c|c|c|c|c|c|c|c|}
\hline \multirow[t]{2}{*}{$\begin{array}{l}\text { IJPDLM } \\
51,4\end{array}$} & Construct & $\begin{array}{l}\text { Model } \\
\text { Path } \\
\text { coefficient }\end{array}$ & $t$-stat & $\begin{array}{l}\text { Mode } \\
\text { Path } \\
\text { coefficient }\end{array}$ & $t$-stat & $\begin{array}{l}\text { Mode } \\
\text { Path } \\
\text { coefficient }\end{array}$ & $t$-stat \\
\hline & $\begin{array}{l}\text { Dependent variable: Returning } \\
\text { satisfaction }\end{array}$ & \multicolumn{2}{|c|}{$R^{2}=0.585$} & & & \multicolumn{2}{|c|}{$R^{2}=0.584$} \\
\hline 414 & $\begin{array}{l}\text { Returning experience } \\
\text { Dependent variable: Purchase }\end{array}$ & \multicolumn{2}{|c|}{$R^{2}=0.288$} & \multicolumn{2}{|c|}{$R^{2}=0.182$} & $\begin{array}{l}0.764 \\
R^{2}=0\end{array}$ & $\begin{array}{l}20.526 \\
888\end{array}$ \\
\hline \multirow{8}{*}{$\begin{array}{l}\text { Table } 6 \text {. } \\
\text { Mediation analysis: } \\
\text { A comparison of the } \\
\text { proposed model (model } \\
\text { 1) to the direct effect } \\
\text { model (model 2) and a } \\
\text { model including both } \\
\text { the direct and indirect } \\
\text { effects (model 3) }\end{array}$} & $\begin{array}{l}\text { satisfaction } \\
\text { Returning satisfaction }\end{array}$ & 0.536 & 11.739 & - & - & 0.508 & 8.243 \\
\hline & Returning experience & & - & 0.426 & 7.993 & 0.037 & 0.525 \\
\hline & Dependent variable: Loyalty & \multicolumn{2}{|c|}{$R^{2}=0.217$} & \multicolumn{2}{|c|}{$R^{2}=0.158$} & \multicolumn{2}{|c|}{$R^{2}=0.221$} \\
\hline & Returning satisfaction & 0.466 & 9.511 & - & - & 0.388 & 4.520 \\
\hline & Returning experience & \multirow{2}{*}{\multicolumn{2}{|c|}{$R^{2}=0.197$}} & 0.398 & 6.844 & 0.101 & 1.089 \\
\hline & Dependent variable: & & & \multicolumn{2}{|c|}{$R^{2}=0.159$} & \multicolumn{2}{|c|}{$R^{2}=0.205$} \\
\hline & Returning satisfaction & 0.444 & 9.720 & - & - & 0.336 & 4.867 \\
\hline & Returning experience & - & - & 0.399 & 8.280 & 0.141 & 1.848 \\
\hline
\end{tabular}

coefficients for the direct effect model (model 2) decreased when the mediator was included (model 3); and for the three outcome variables, the direct effect path coefficients went from significant to nonsignificant. Collectively, these insights provide support that return satisfaction mediates the relationship between return experience and the three outcome variables.

The effect of planned versus unplanned returns on customer outcomes. The second research objective was to see if the model is moderated by the reason for returning the item(s). Harris (2008) draws attention to the disconcerting rise in fraudulent returns; however, not all product returners are of such a devious disposition. Scholars have suggested that customers be segmented based on returning tendency (Hjort and Lantz, 2012, 2016), but we are unaware of any research having done so. Even omitting fraudulent returns, scholars have identified that some returns are planned, such as ordering multiple products with the intentions of only keeping one (Saarijärvi et al., 2017). Recall that in some countries returning items is a right, requiring no explanation.

Survey respondents were therefore divided into two groups based on their main reason for returning the fashion item(s). Subjects were presented a list containing 22 reasons for returning fashion merchandise identified by Saarijärvi et al. (2017, refer to their Table 1), and from this list asked to indicate the most important reason for their product return. Fifteen of the reasons were $a$ priori classified as an unplanned reason to return (e.g. "misleading product picture", "the product has defects"), five were classified as planned returns (e.g. "ordering many sizes of the same product with the intention to keep only one", "ordering alternative products for the same need with the intention not to keep all of them") and two were considered neither planned or unplanned ("cannot actually afford to keep the product"). Of the 384 participants, 310 indicated an unplanned reason, $73(19 \%)$ chose a planned reason, and one indicated that they could not afford the item(s). The latter participant was removed from further analysis.

When comparing the path coefficients for the unplanned return group to the planned return group (top- and bottom-values, respectively, in Figure 2), returning experience explains return satisfaction in both groups, and returning satisfaction explains overall satisfaction and WOM. The noteworthy difference concerns loyalty: the relationship between return satisfaction and loyalty is not significant for planned returners.

However, the path coefficients are not the whole story. Table 7 compares the mean values for both groups for the three outcome variables. The findings show that planned returners 


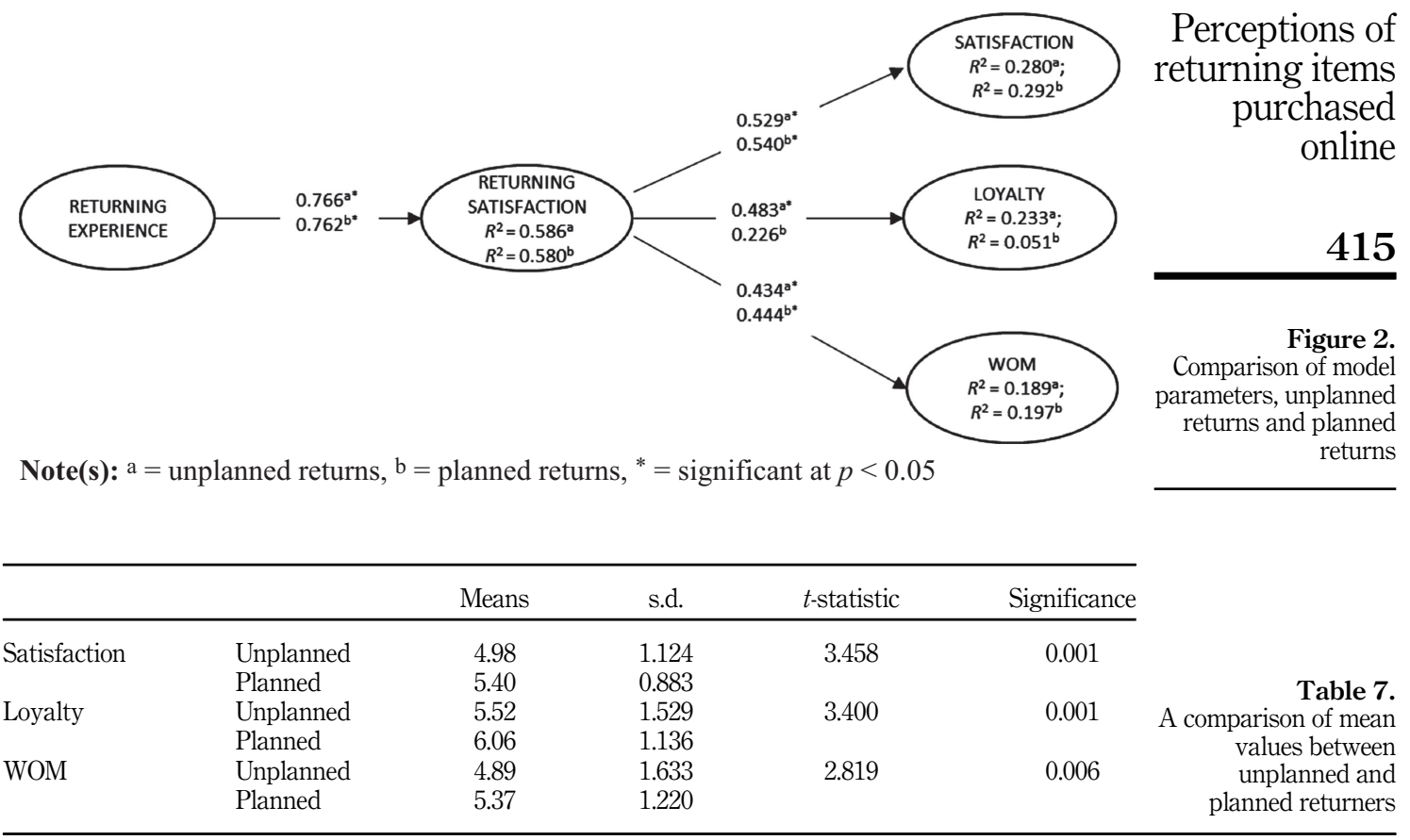

have significantly higher levels of satisfaction with the organization, loyalty and intentions to recommend the firm than do unplanned returners. Although unplanned returners have significantly lower loyalty - their return was due to some form of service failure - given the significant relationship between return satisfaction and loyalty, by better managing the return process for unplanned returners' organizations can increase loyalty.

\section{Discussion}

Optimizing returns management entails contrasting goals: on one hand, it is desirable to cut down the rate of returns, and on the other hand, create customer value, which might in some cases increase the volumes of returns (Hjort et al., 2019). With deeper customer insights these seemingly opposite goals may both be feasible. As Fuller et al. (1993, p. 87) noted nearly 30 years ago: "Customer needs vary, and companies can tailor their logistics systems to serve their customers better and more profitably. Companies do not create value for customers and sustainable advantage for themselves merely by offering varieties of goods. Rather, they offer goods in distinct ways." Here we shed light on reasons for returning products as well as the implications of the product return experience, insights of which can be used to tailor a returns management strategy.

Within returns management, return policies (e.g. the allowable time to return items) are acknowledged as a factor affecting sales, return proclivity and ultimately profitability (Janakiraman et al., 2016; Petersen and Kumar, 2009). They are an increasingly important part of the firm's overall offering, particularly for online retailers where the purchase decision and the decision to keep the good(s) are temporally separated (Wood, 2001). Largely absent from existing research are the ramifications of the returning experience from the customer's perspective (Ertekin, 2018). Conceptualizing the returning experience as an antecedent of 
IJPDLM 51,4

returning satisfaction, which in turn influences overall satisfaction, loyalty and WOM was the raison d'etre of this study. The overarching goal was to introduce and test a parsimonious model that links returning experience to these outcomes that ultimately affect a firm's profitability.

Qualitative insights revealed perceptions underlying the returning experience, notably the monetary cost, convenience, stress and guilt. We believe this is among the first studies to provide evidence regarding the emotions experienced during the returning process. Earlier research has addressed product return policies such as free versus fee returns (Bower and Maxham, 2012), and waiting time for replacing products or getting refunded (Hall et al., 2013); this research effort focuses on how customers perceive the returning experience. Thus, we broaden the current view from rational to emotional aspects of returning products. Our results also show that the returning experience contributes to returning satisfaction. This is the first study to introduce returning satisfaction as a separate construct, which was shown to mediate the relationship between returning experience and overall satisfaction, loyalty and WOM.

Returning products involves multiple touchpoints, some of which the firm has little control, such as repackaging the product or the customer going to the post office. Nevertheless, these interactions are ultimately related to the firm, driving perceptions of the returning experience, a component within the consumer's overall experiential journey. This may explain why those that had unplanned returns gave lower overall satisfaction, loyalty and WOM ratings than did planned returners. Regardless of how well the return process was, it was unwanted and thus appears to have lowered the overall experience with the organization. Prior research (Walsh and Brylla, 2017) has shown that returns can lower customer satisfaction, but this study did not separate planned from unplanned returners nor did it examine the emotions experienced. While we did not study the ramifications of the four individual components comprising the returning experience, we can speculate that unplanned returners may have experienced greater levels of guilt and stress than did planned returners. Planned returners, those that intentionally overorder items, are probably more cognizant of the firm's return policies, particularly policies related to costs and convenience, and are less likely to feel guilty given their planned actions. This may also explain why planned returners had higher levels of overall satisfaction, loyalty and WOM. A post hoc comparison of the mean scores for the four components comprising the Returning Experience did not, however, return statistically significant differences between planned and unplanned returners; but the means for the four measures were all lower for unplanned returners suggesting that they were less likely to agree that returning items, for example, "did not cause stress". For online retailers, this raises the question of whether there is an optimal level of satisfaction - at least when it comes to returning items.

Research in offline contexts has shown that in-store return experiences affect satisfaction and future purchases (Ertekin, 2018). We show that return satisfaction mediates the relationship between returning experience and overall satisfaction with the retailer, loyalty and WOM (refer to Figure 1). By showing the ramifications that the returning experience has on these customer outcomes via return satisfaction, these insights provide psychological evidence that backs Petersen and Kumar's (2015) empirical insight that product returns should not be considered solely as a cost to the firm. They found that properly managed product returns can increase CLV, for example, by affecting how the marketing budget is allocated. We show how product returns affect satisfaction, loyalty and WOM, insights that should be considered by those responsible for setting return policies. Unlike prior work (Janakiraman et al., 2016), the returning experience was introduced as a concept independent of actual return policies, thus shifting the focus from a company centric view to a customer centric view. Studies investigating the effect of returning proclivity on sales volumes, 
profitability and CLV (Petersen and Kumar, 2009, 2015) would likely benefit from incorporating whether the return experience is deemed good or bad.

\section{Managerial implications}

It has long been acknowledged that supply chain managers should focus on customer value and satisfaction (Fuller et al., 1993; Daugherty et al., 2019). Now, managers use return policies as a tool to affect the firm's competitive positioning, with the general orientation to offer lenient return policies, such as offering return windows longer than is legally required, if applicable (e.g. 14 days in the European Union). This study unearthed four factors affecting consumers' perceptions of the return experience - monetary costs, convenience, stress and guilt - that should be taken into consideration when developing return policies. In addition, our approach emphasized the reason for returns (planned versus unplanned). Hence, the obvious but rarely discussed implication points to the importance of understanding that perceptions of the returning process based on the very same return policy may differ. Understanding the reason for return and the drivers of the returning experience may help make sense of why returns happen, and what to do with these insights. For example, retailers can proactively address the emotional drivers of return experience with statements such as "we take the hassle out of shopping" (stress reduction) and "we understand that mistakes happen" (guilt reduction). But should all customers be treated equally?

Empirical findings revealed that planned returners had higher satisfaction, loyalty and positive WOM ratings relative to unplanned returners. While it would be difficult to dispute the benefits of WOM, the loyalty of planned returners - driven by lenient exchange policies may very well be unprofitable for the organization (Keiningham and Aksoy, 2009). Assumptions should therefore be tested for what differentiates planned from unplanned returners. Planned returners can likely be identified by analyzing shopping baskets and order histories for cases where variations (size, color) of the same item have been ordered and only one version (or a subset) kept. Firms should also consider how many prior interactions with the firm ended-up involving returned items as well as the percentage of items returned during a single purchase. Activity-based customer costing has an established history, insights of which should be used to treat customers differently (Shin et al., 2012). If two or more returning segments emerged, this would re-enforce a recommendation by Hjort and Lantz $(2012,2016)$ that not all customers should be extended the same return conditions. Planned returners should have stricter return policies, such as charging a fee to return products. In extreme cases, the organization should "fire the customer", as some suggest (Keiningham and Aksoy, 2009; Shin et al., 2012). Thus, although lenient return policies are a means to mitigate purchase risk, hence attract consumers, in the case of planned returners heightening the risk (having stricter policies) seems appropriate. Firms should therefore investigate if it is appropriate from a CLV perspective to have targeted return policies - advancements in data analytics make this feasible. Alternatively, they could invoke general policies that have a targeted effect. For example, indicating that there is no fee to return the first item, but the fee increases for each additional item returned. If the customer's purchase history suggests that they are unplanned returners, extending their customer experience by following-up the return with a letter from the company signaling that they are a trusted and valued customer would likely raise satisfaction and loyalty. One should assume that the effect on the bottom line of product returns is not the same across companies; hence, where to draw the line in tolerating planned returns depends on the relational cost efficiency of reverse logistics, further emphasizing the role of analytics in today's online retail operations.

Lastly, our empirical findings suggest a tempting implication for managers: investing in managing the return experience has the potential of delivering the best of both worlds, as it
Perceptions of returning items purchased online 
IJPDLM 51,4

increases the loyalty of unplanned returners but has milder effect (i.e. not statistically significant) when it comes to the loyalty of planned returners. Although the planned returners had higher loyalty than unplanned returners, it was the unplanned returners whose loyalty could be increased according to our findings.

\section{Avenues for future research and limitations}

This study proposed that the return experience and return satisfaction are missing links between return policy leniency, return proclivity and firm performance. Several issues present themselves as avenues for follow-on research. The first concerns further analysis into what drives perceptions of the returning experience. The four characteristics that emerged here tap both cognitions and emotions. Are these four sufficiently comprehensive? The pilot study involved students and staff members at a university in Finland and are thus not representative of the population, which should be considered a limitation. Given the importance of the return experience, more research is therefore encouraged. We further acknowledge that both the pilot study and the main study pertained to returning fashion items. Although fashion merchandise is the largest e-commerce category (Postnord 2016; Statista 2018), broadening the product categories studied and countries studied could prove enlightening.

Prior studies have compared nonreturners to returners, and generally concluded the former are more profitable (Hjort and Lantz, 2016; Petersen and Kumar, 2009; Griffis et al., 2012; but see Hjort and Lantz, 2012). Another study showed that taking product returns into consideration can enhance CLV (Petersen and Kumar, 2015). Here, we show that of those that did return items there are at least two groups: planned returners and unplanned returners. We encourage more work regarding how to segment customers based on their return behavior/why they returned the item(s) as well as the ramifications that these segments have on the bottom-line. Finally, unexplored here are how problems experienced in the return process (e.g. finding purchase-related documents, queues at the post office) hamper these same outcomes. For example, it would be interesting to address questions such as "how a poor returning experience contributes to negative WOM", a growing concern amplified by social media usage.

These limitations and directions for future research aside, our aspiration is that drawing attention to the returning experience and its ramifications will attract follow-on studies that inform managers of the importance of the return experience and its role within the product returns management domain.

\section{Notes}

1. Rose et al. (2012) focus on the customer's experience in an online context but did not consider the return experience.

2. Bergkvist and Rossiter (2007) tested the predictive validity of multi-item vs single item constructs and discuss conditions when the use of single-item measures is appropriate. Although attitude was used as a construct in their empirical tests, they note that "the findings should generalize to other concrete attributes, such as beliefs or perceptions, intentions and satisfaction" (Bergkvist and Rossiter, 2007, p. 183). They point to Rossiter's C-OAR-SE procedure for scale development: "if the object can be conceptualized as concrete and singular, it does not require multiple items to represent it in the measure, and if the attribute can be conceptualized as concrete, it does not require multiple items either" (Bergkvist and Rossiter, 2007, p. 175). They also argue that single-item measures are recommended in cases where common method bias might be a concern, which we recognized as a potential risk. In our case, "returning satisfaction" is based on a single, concrete event (product return), whereas "satisfaction" measures the more abstract, overall perception of the retailer using an accepted three-item scale. 


\section{References}

Baxendale, S., Macdonald, E.K. and Wilson, H.N. (2015), "The impact of different touchpoints on brand consideration", Journal of Retailing, Vol. 91 No. 2, pp. 235-253.

Bergkvist, L. and Rossiter, J.R. (2007), "The predictive validity of multiple-item versus singleitem measures of the same constructs", Journal of Marketing Research, Vol. 44 No. 2, pp. 175-184.

Bower, A.B. and Maxham, J.G. III (2012), "Return shipping policies of online retailers: normative assumptions and the long-term consequences of fee and free returns", Journal of Marketing, Vol. 76 No. 5, pp. $110-124$.

Bustamante, J.C. and Rubio, N. (2017), "Measuring customer experience in physical retail environments", Journal of Service Management, Vol. 28 No. 5, pp. 884-913.

Cassill, N.L. (1998), "Do customer returns enhance product and shopping experience satisfaction?", The International Review of Retail, Distribution and Consumer Research, Vol. 8 No. 1, pp. 1-13.

Chin, W.W. (1998), "The partial least squares approach to structural equation modeling", Modern Methods for Business Research, Vol. 295 No. 2, pp. 295-336.

Chin, W.W. and Newsted, P.R. (1999), "Structural equation modeling analysis with small samples using partial least squares", in Hoyle, R.H. (Ed.), Statistical Strategies for Small Sample Research, Sage Publications, Thousand Oaks: CA, pp. 307-341.

Cohen, J. (1988), Statistical Power Analysis for the Behavioral Sciences, Routledge Academic, New York, NY.

Dailey, L.C. and Ülkü, M.A. (2018), "Retailers beware: on denied product returns and consumer behavior", Journal of Business Research, Vol. 86, pp. 202-209.

Daugherty, P.J., Bolumole, Y. and Grawe, S.J. (2019), "The new age of customer impatience", International Journal of Physical Distribution and Logistics Management, Vol. 49 No. 1, pp. 4-32.

de Leeuw, S., Minguela-Rata, B., Sabet, E., Boter, J. and Sigurðardóttir, R. (2016), "Trade-offs in managing commercial consumer returns for online apparel retail", International Journal of Operations and Production Management, Vol. 36 No. 6, pp. 710-731.

Ertekin, N. (2018), "Immediate and long-term benefits of in-store return experience", Production and Operations Management, Vol. 27 No. 1, pp. 121-142.

European Union (2019), "Help and advice for EU nationals and their family", available at: https:// europa.eu/youreurope/citizens/consumers/shopping/guarantees-returns/index_en.htm.

Fornell, C. and Larcker, D.F. (1981), "Structural equation models with unobservable variables and measurement error: algebra and statistics", Journal of Marketing Research, pp. 382-388.

Frow, P. and Payne, A. (2007), “Towards the 'perfect' customer experience”, Journal of Brand Management, Vol. 15 No. 2, pp. 89-101.

Fuller, J.B., O'Conor, J. and Rawlinson, R. (1993), “Tailored logistics: the next advantage”, Harvard Business Review, Vol. 71 No. 3, pp. 87-98.

Gligor, D., Bozkurt, S., Gölgeci, I. and Maloni, M.J. (2020), "Does supply chain agility create customer value and satisfaction for loyal B2B business and B2C end-customers?", International Journal of Physical Distribution and Logistics Management, Vol. 50 Nos 7/8, pp. 721-743.

Grewal, D., Levy, M. and Kumar, V. (2009), "Customer experience management in retailing: an organizing framework", Journal of Retailing, Vol. 85 No. 1, pp. 1-14.

Griffis, S.E., Rao, S., Goldsby, T.J. and Niranjan, T.T. (2012), "The customer consequences of returns in online retailing: an empirical analysis", Journal of Operations Management, Vol. 30 No. 4, pp. 282-294.

Hair, J.F., Sarstedt, M., Ringle, C.M. and Mena, J.A. (2011), "An assessment of the use of partial least squares structural equation modeling in marketing research", Journal of the Academy of Marketing Science, Vol. 40 No. 3, pp. 414-433.

Perceptions of returning items purchased online

\section{$-$}


IJPDLM 51,4

Hall, D.J., Huscroft, J.R., Hazen, J.B. and Hanna, J.B. (2013), "Reverse logistics goals, metrics, and challenges: perspectives from industry", International Journal of Physical Distribution and Logistics Management, Vol. 43 No. 9, pp. 768-785.

Harris, L.C. (2008), "Fraudulent return proclivity: an empirical analysis", Journal of Retailing, Vol. 84 No. 4, pp. 461-476.

Harris, L.C. (2010), "Fraudulent consumer returns: exploiting retailers' return policies", European Journal of Marketing, Vol. 44 No. 6, pp. 730-747.

Henseler, J., Ringle, C.M. and Sinkovics, R.R. (2009), The Use of Partial Least Squares Path Modeling in International Marketing, Emerald Group Publishing, Bingley, pp. 277-319.

Hjort, K. and Lantz, B. (2012), "(R)e-tail borrowing of party dresses: an experimental study", International Journal of Retail and Distribution Management, Vol. 40 No. 12, pp. 997-1012.

Hjort, K. and Lantz, B. (2016), "The impact of returns policies on profitability: a fashion e-commerce case", Journal of Business Research, Vol. 69 No. 11, pp. 4980-4985.

Hjort, K., Hellström, D., Karlsson, S. and Oghazi, P. (2019), "Typology of practices for managing consumer returns in internet retailing", International Journal of Physical Distribution and Logistics Management, Vol. 49 No. 7, pp. 767-790.

Homburg, C., Jozić, D. and Kuehnl, C. (2017), "Customer experience management: toward implementing an evolving marketing concept", Journal of the Academy of Marketing Science, Vol. 45 No. 3, pp. 377-401.

Ieva, M. and Ziliani, C. (2018), "Mapping touchpoint exposure in retailing", International Journal of Retail and Distribution Management, Vol. 46 No. 3, pp. 304-322.

Janakiraman, N., Syrdal, H.A. and Freling, R. (2016), "The effect of return policy leniency on consumer purchase and return decisions: a meta-analytic review", Journal of Retailing, Vol. 92 No. 2, pp. 226-235.

Jones, M.A. and Reynolds, K.E. (2006), "The role of retailer interest on shopping behavior", Journal of Retailing, Vol. 82 No. 2, pp. 115-126.

Keiningham, T. and Aksoy, L. (2009), "When customer loyalty is a bad thing", Harvard Business Review - The Daily Alert, Vol. 9, May, available at: https://hbr.org/2009/05/when-customerloyalty-is-a-bad.

King, T., Dennis, C. and McHendry, J. (2007), "The management of deshopping and its effects on service: a mass market case study", International Journal of Retail and Distribution Management, Vol. 35 No. 9, pp. 720-733.

Lemon, K.N. and Verhoef, P.C. (2016), "Understanding customer experience throughout the customer journey", Journal of Marketing, Vol. 80 No. 6, pp. 69-96.

Mägi, A.W. (2003), "Share of wallet in retailing: the effects of customer satisfaction, loyalty cards and shopper characteristics", Journal of Retailing, Vol. 79 No. 2, pp. 97-106.

Markley, M.J. and Davis, L. (2007), "Exploring future competitive advantage through sustainable supply chains", International Journal of Physical Distribution and Supple Chain Management, Vol. 37 No. 9, pp. 763-774.

McColl-Kennedy, J.R., Zaki, M., Lemon, K.N., Urmetzer, F. and Neely, A. (2019), "Gaining customer experience insights that matter", Journal of Service Research, Vol. 22 No. 1, pp. 8-26.

Mollenkopf, D. (2014), "What does it take to get published these days?", International Journal of Physical Distribution and Logistics Management, Vol. 44 No. 3, doi: 10.1108/IJPDLM-02-2014-0019.

Mollenkopf, D.A., Rabinovich, E., Laseter, T.M. and Boyer, K.H.K. (2007), "Managing internet product returns: a focus on effective service operations", Decision Sciences, Vol. 38 No. 2, pp. 215-250.

Mollenkopf, D.A., Frankel, R. and Russo, I. (2011), "Creating value through returns management: exploring the marketing-operations interface", Journal of Operations Management, Vol. 29 No. 5, pp. 391-403. 
National Retail Federation (2015), "2015 Consumer returns in the retail industry: annual return survey", available at: https://nrf.com/sites/default/files/Images/Media \%20Center/NRF\% 20Retail\%20Return\%20Fraud\%20Final_0.pdf.

Optoro (2018), "RARC Report riding the returns wave: reverse logistics and the U.S. Postal Service", available at: https://www.uspsoig.gov/sites/default/files/document-library-files/2018/RARC-WP18-008.pdf.

Petersen, J.A. and Kumar, V. (2009), "Are product returns a necessary evil? Antecedents and consequences", Journal of Marketing, Vol. 73 No. 3, pp. 35-51.

Petersen, J.A. and Kumar, V. (2015), "Perceived risk, product returns, and optimal resource allocation: evidence from a field experiment", Journal of Marketing Research, Vol. 70, April, pp. 268-285.

Piron, F. and Young, M. (2001), "Retail borrowing: definition and retailing implications", Journal of Retailing and Consumer Services, Vol. 8 No. 3, pp. 121-125.

Postnord (2016), "E-commerce in europe", available at: https://www.postnord.com/globalassets/global/ english/document/publications/2016/e-commerce-in-europe-2016.pdf.

Rao, S., Lee, K.B., Connelly, B. and Iyengar, D. (2018), "Return time leniency in online retail: a signaling theory perspective on buying outcomes", Decision Sciences, Vol. 49 No. 2, pp. 275-305.

Ringle, C.M., Wende, S. and Becker, J.M. (2015), SmartPLS 3, SmartPLS GmbH, Boenningstedt.

Robertson, T.S., Hamilton, R. and Jap, S.D. (2020), "Many (un)happy returns? The changing nature of retail product returns and future research directions", Journal of Retailing, Vol. 96 No. 2, pp. 172-177.

Rogers, D.S. and Tibben-Lembke, R. (2001), “An examination of reverse logistics practices”, Journal of Business Logistics, Vol. 22 No. 2, pp. 129-148.

Rogers, D.S., Croxton, K.L., Garcia-Dastugue, S.J. and Lambert, D.M. (2002), "The returns management process", International Journal of Logistics Management, Vol. 13 No. 2, pp. 1-18.

Rose, S., Clark, M., Samouel, P. and Hair, N. (2012), "Online customer experience in e-retailing: an empirical model of antecedents and outcomes", Journal of Retailing, Vol. 88 No. 2, pp. 308-322.

Saarijärvi, H., Sutinen, U.-M. and Harris, L.C. (2017), “Uncovering consumers' returning behaviour: a study of fashion e-commerce", The International Review of Retail, Distribution and Consumer Research, Vol. 27 No. 3, pp. 284-299.

Shin, J., Sudhir, K. and Yoon, D. (2012), "When to 'fire' customers: customer cost-based pricing", Management Science, Vol. 58 No. 5, pp. 932-947.

Statista (2018), "eCommerce report 2018 - fashion", available at: https://www.statista.com/study/38340/ ecommerce-report-fashion/.

Tehseen, S., Ramayah, T. and Sajilan, S. (2017), "Testing and controlling for common method variance: a review of available methods", Journal of Management Sciences, Vol. 4 No. 2, pp. 142-168.

Vakulenko, Y., Hellström, D. and Hjort, K. (2018), "What's in the parcel locker? Exploring customer value in e-commerce last mile delivery”, Journal of Business Research, Vol. 88, pp. 421-427.

Verhoef, P.C., Lemon, K.N., Parasuraman, A., Roggeveen, A., Tsiros, M. and Schlesinger, L.A. (2009), "Customer experience creation: determinants, dynamics and management strategies", Journal of Retailing, Vol. 85 No. 1, pp. 31-41.

Walsh, G. and Brylla, D. (2017), "Do product returns hurt relational outcomes? Some evidence from online retailing", Electronic Markets, Vol. 27 No. 4, pp. 329-339.

Wood, S.L. (2001), "Remote purchase environments: the influence of return policy leniency on twostage decision processes", Journal of Marketing Research, Vol. 38 No. 2, pp. 157-169.
Perceptions of returning items purchased

\section{online}

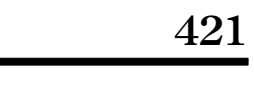


IJPDLM 51,4

\section{About the authors}

Timo Rintamäki is an Associate Professor of Insurance Science at the Faculty of Management and Business, Tampere University, Finland. His research interests include customer value, decisionmaking and service management. He has recently published, for example, in Industrial Marketing Management, International Journal of Retail and Distribution Management, Journal of Retailing and Consumer Services, and AMS review. Timo Rintamäki is the corresponding author and can be contacted at: timo.rintamaki@tuni.fi

Mark T. Spence is a Professor of Marketing at the Bond Business School, Australia. His research interests are situated in the field of behavioral decision-making. His research has been published in, for example, Journal of Marketing Research, Journal of Consumer Research, European Journal of Marketing, Psychology and Marketing and Journal of Retailing.

Hannu Saarijärvi is a Professor of Marketing at the Faculty of Management and Business, Tampere University, Finland. His research interests lie in value cocreation, service marketing and customer relationship management. He has published, for example, in Industrial Marketing Management, European Business Review and Journal of Strategic Marketing.

Johanna Joensuu is a researcher at the Faculty of Management and Business, Tampere University, Finland. Her background is in Statistics, and she has recently published in International Journal of Retail and Distribution Management, and International Review of Retail, Distribution and Consumer Research.

Mika Yrjölä is a University Lecturer of Marketing at the Faculty of Management and Business, Tampere University, Finland. His research background is on executive decision-making, business models, digital services and omni-channel retailing. He has published his work in the Journal of Retailing and Consumer Services, European Business Review, and Journal of Business and Industrial Marketing.

For instructions on how to order reprints of this article, please visit our website: www.emeraldgrouppublishing.com/licensing/reprints.htm Or contact us for further details: permissions@emeraldinsight.com 